DOI: $10.4274 /$ jarem.galenos.2020.3268

J Acad Res Med 2020;10(2):155-9

\title{
Assessment of Speech Intelligibility in Free-field Sound Chamber at Different Signal Noise Ratios
}

\author{
(1) Zahra Polat1, (1)Ahmet Ataş2 \\ ${ }^{1}$ University of Health Sciences Turkey, Hamidiye Faculty of Health Sciences, İstanbul, Turkey \\ ${ }^{2}$ istanbul University-Cerrahpaşa, Cerrahpaşa Faculty of Medicine, Department of Otolaryngology, İstanbul, Turkey
}

Cite this article as: Polat Z, Ataş A. Assessment of Speech Intelligibility in Free-field Sound Chamber at Different Signal Noise Ratios.

J Acad Res Med 2020;10(2):155-9

\begin{abstract}
Objective: In the presence of background noise, understanding speech is challenging for any listener, especially for those with serious hearing loss. This study aimed to determine speech intelligibility of normal-hearing adults in quiet and noisy free fields.

Methods: This study included 77 volunteers with normal hearing aged between 18 and 30 years (mean: $22.25 \pm 2.7$ years). Speech intelligibility scores were determined using the non-adaptive method at different signal-to-noise ratios (SNRs) and changing the noise direction (front and rear).

Results: The mean \pm standard deviation of the adaptive matrix speech reception threshold in quiet for $50 \%$ intelligibility was $22.69 \pm 3 \mathrm{~dB}$ sound pressure level. Speech intelligibility scores obtained at $-10,-5$, and $0 \mathrm{~dB}$ SNRs were significantly different when the noise was presented from the front to rear direction $(p<0.05)$. Better speech intelligibility scores were obtained when noise was presented from the rear.

Conclusion: The standard audiometric test battery does not measure speech intelligibility in noisy environments. Therefore, speech intelligibility in the noise test developed and normalized in the native language of the patient should be used in the evaluation. Because our study was conducted in free field, the results could be used in the evaluation of patients using cochlear implants and hearing aids in free field.
\end{abstract}

Keywords: Speech audiometry, speech intelligibility in noise, signal-to-noise ratio, speech reception threshold, Turkish matrix sentence test

\section{INTRODUCTION}

Better speech perception is essential to improve communication. Understanding speech in the presence of background noise is challenging for any listener, especially for those with serious hearing loss. In our daily life, our environments are often noisy. The most common complaint by normal individuals and patients with hearing loss is the difficulty in understanding speech in noisy environments.

Most speech audiometry tests evaluate the performance of the listener in a quiet environment. However, the signal-to-noise ratio (SNR) and speech perception performance in background noise are of paramount importance because individuals have to understand speech in the presence of other signals found in their natural environments. Hence, speech-in-noise tests were developed. Speech-in-noise tests are also useful for adjusting classroom acoustics, setting hearing aids, hearing screening, and in the field of telecommunications (1).

Monosyllabic/polysyllabic words or phrases may be used as the test material in speech tests. Although the use of words offers the advantage of testing speech in an isolated way, the use of materials, such as long sentences, offers the advantage of testing more than one word at a time. Therefore, the use of sentences as the material is more efficient in a speech discrimination

ORCID IDs of the authors: Z.P. 0000-0001-8384-4302; A.A. 0000-0002-8673-6793. 
performance assessment (2). The use of sentences also means that the test better reflects communication in daily life. The matrix test was first prepared in Swedish by Hagerman (3). In 1999, Wagener et al. (4) detailed the test by attempting to create a natural prosody and adapted it to German.

Despite the limited word material [a sentence composed of 5-word types (e.g., verb, noun, subject, etc.) with 10 different words for each type], 100,000 combinations are possible. Phonetic distribution has been carried out in accordance with the language of the test. In practice, because the material provides an unlimited number of sentences, the matrix sentence test suitable for use in research and rehabilitation requires repeated testing (5). The matrix test in Turkish used in this study was created in 2015 (6).

This study aimed to determine the speech discrimination scores (SDSs) of young adults with normal hearing in quiet and noisy free fields. Because testing cochlear implant $(\mathrm{Cl})$ and hearing aid users with headphones is impractical, normative data are required for the noisy free field. Additionally, the placement and direction of the microphone in the hearing aid and $\mathrm{Cls}$ has an effect on understanding speech in noise. Therefore, the difference in subjects' speech intelligibility performance in relation to the direction of the noise was obtained.

\section{METHODS}

This study was constructed and conducted in compliance with the Helsinki Declaration of ethical standards and approved by the institutional ethics committee. Ethics committee approval was received from the İstanbul university-Cerrahpaşa, Cerrahpaşa Faculty of Medicine Clinical Research Ethics Committee for approval of the study (approval number: 83045809-604.01.02). All participants were informed in detail about the procedures of this study and signed an informed consent form.

This study included 77 native Turkish speakers aged between 18 and 30 years ( 55 women, 22 men). Their mean age was $22.25 \pm 2.7$ years. All volunteers underwent otoscopic examination and tympanometric measurements. Subsequently, pure tone and speech audiometry test batteries were conducted. All participants had hearing thresholds better than $15 \mathrm{~dB}$ between 250 and 8000 $\mathrm{Hz}$. They had $<10 \mathrm{~dB}$ air-bone gap between 250 and $4000 \mathrm{~Hz}$. All study participants had type A tympanograms. The participants' speech reception thresholds (SRTs) and SDSs were determined before the Turkish matrix test measurements.

The speech intelligibility scores were measured using the Turkish matrix test in quiet and noisy environments. As recommended by Wagener et al. (4), two practice sessions (one in a quiet environment and one in a noisy environment) took place before the measurements (7).

\section{Measurement Setup}

The subjects were situated in a double-walled sound chamber containing two speakers, one in front and one behind the subject at an azimuth of $180^{\circ}$. An audiometer (AURICAL Aud; Otometrics, Denmark) with the "Oldenburg Measurement Applications
(HörTech, Germany)" software was used. Figure 1 illustrates the measurement setup.

The Turkish adaptive and non-adaptive matrix test was used to measure the subjects' speech intelligibility in quiet and noisy environments. The test lists composed of 20 sentences were used as test material. The noise stimulus was a bubble noise set to continuous mode at $65 \mathrm{~dB}$ SPL. The measurements listed in Table 1 were conducted for all subjects. If necessary, the subjects were allowed to take a break.

\section{Statistical Analysis}

Statistical analysis was performed using SPSS 20.0 for Windows (IBM Corporation, New York, USA). The normality of the variables was assessed using the Shapiro-Wilk test provided by the SPSS software. The significance of the difference between measurements was analyzed using the Mann-Whitney $U$ test. The correlation analysis was conducted by applying the Spearman rho test. The results were considered significant if $\mathrm{p} \leq 0.05$.

\section{RESULTS}

For each subject, the pure tone thresholds were measured in free field for 500, 1000, 2000, and $4000 \mathrm{~Hz}$, and the pure tone averages (PTAs) were calculated. The mean \pm standard deviation (SD) of the PTA was $3.73 \pm 2.8 \mathrm{~dB} \mathrm{HL}$. The SDSs of all subjects measured in quiet free field were $>88 \%$.

Table 2 shows the mean \pm SD of the matrix test measurements, and Figure 2 shows the mean speech intelligibility of the subjects for different SNRs and noise presentation conditions. As shown in Figure 2, the performance differences between the two conditions increased as the SNR decreased.

Table 3 shows the difference between the performances when the noise is from different directions. The intelligibility scores obtained at $-10,-5$, and $0 \mathrm{~dB}$ SNR when noise was from the rear were significantly different from the scores when noise was from the front $(p<0.05)$.

The adaptive matrix SRT in noise values were also obtained for different SNRs when noise and signal were both from the front, and this difference was also statistically significant $(p<0.05)$. The performances remained unchanged as the SNR increased; hence, statistically significant differences were not found for +5 and +10 dB SNR. This effect can be seen in Table 4.

\section{DISCUSSION}

The standard audiometric test battery does not measure speech intelligibility in noise (8). The SRT is a test based on the signal-to-

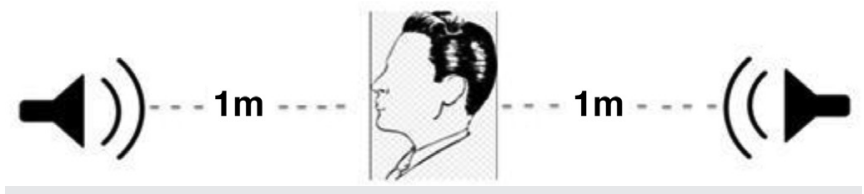

Figure 1. Measurement setup 
sentences is not suitable for repeated testing. For example, the quick speech in noise (QuickSIN) test is composed of 1800 key words used in 360 different sentences (9).

Table 2. Descriptive statistics of measurements using hearing aid or $\mathrm{Cl}$ is good in a quiet environment, it is disturbed in noisy listening conditions. Therefore, speech intelligibility in noise tests has been developed in different languages.

Although the developed tests are useful due to the correct SRT estimation, the use of a limited number of words, phrases, or

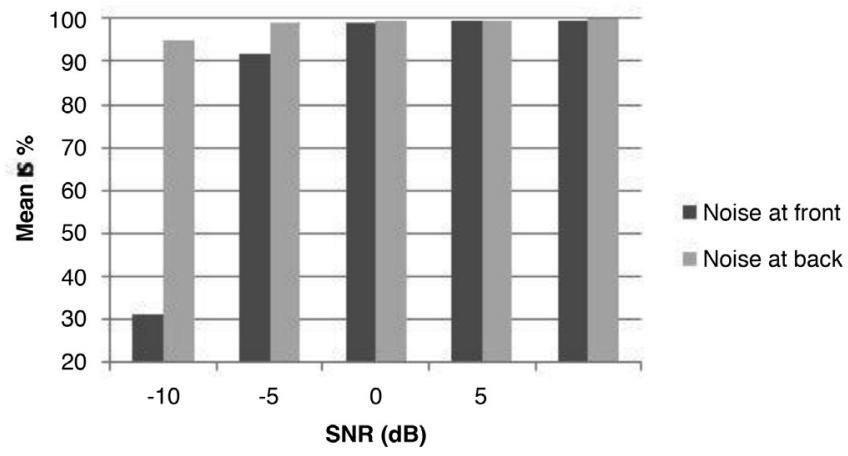

Figure 2. Mean speech intelligibility scores of subjects for different signal-to-noise ratios SNR: Signal-to-noise-ratios

\section{Table 1. Measurements conducted for each subject}

\section{No Measurement}

1 Adaptive matrix SRT in quiet (50\%)

2 Adaptive matrix SRT in noise (50\%)

3 Adaptive matrix SRT in noise (50\%)

4 Non-adaptive intelligibility score in quiet (65 dB SPL)

$5 \quad$ Non-adaptive intelligibility score in noise (-10 dB SNR)

Non-adaptive intelligibility score in noise (-5 dB SNR)

$7 \quad$ Non-adaptive intelligibility score in noise (0 dB SNR)

8 Non-adaptive intelligibility score in noise (5 dB SNR)

9 Non-adaptive intelligibility score in noise (10 dB SNR)

Non-adaptive intelligibility score in noise (-10 dB SNR)

Non-adaptive intelligibility score in noise (-5 dB SNR)

12

Non-adaptive intelligibility score in noise (0 dB SNR)

13 Non-adaptive intelligibility score in noise (5 dB SNR) noise (10 dB SNR)

Direction of noise

Noise in front

Noise in rear

Noise in front

Noise in front

Noise in front

Noise in front

Noise in front

Noise in rear

Noise in rear

Noise in rear

Noise in rear

Noise in rear

dB: Decibel, SNR: signal to noise ratio, SPL: Sound pressure level, SRT: speech reception threshold

\begin{tabular}{|c|c|c|c|}
\hline Measurements & $\begin{array}{l}\text { Speech } \\
\text { position }\end{array}$ & $\begin{array}{l}\text { Noise } \\
\text { position }\end{array}$ & $\begin{array}{l}\text { Measured } \\
\text { values (mean } \\
\pm \text { SD) }\end{array}$ \\
\hline $\begin{array}{l}\text { Adaptive matrix SRT in } \\
\text { quiet }(50 \%)\end{array}$ & Front & - & $\begin{array}{l}22.69 \pm 3.0 \mathrm{~dB} \\
\mathrm{SPL}\end{array}$ \\
\hline $\begin{array}{l}\text { Adaptive matrix SRT in } \\
\text { noise }(50 \%)\end{array}$ & Front & Front & $\begin{array}{l}-7.92 \pm 0.8 \mathrm{~dB} \\
\text { SNR }\end{array}$ \\
\hline $\begin{array}{l}\text { Adaptive matrix SRT in } \\
\text { noise }(50 \%)\end{array}$ & Front & Rear & $\begin{array}{l}-15.12 \pm 2.8 \mathrm{~dB} \\
\text { SNR }\end{array}$ \\
\hline $\begin{array}{l}\text { Non-adaptive intelligibility } \\
\text { score in quiet }\end{array}$ & Front & - & $99.16 \pm 1.6 \%$ \\
\hline $\begin{array}{l}\text { Non-adaptive intelligibility } \\
\text { score in quiet (-10 dB SNR) }\end{array}$ & Front & Front & $31.10 \pm 11.9 \%$ \\
\hline $\begin{array}{l}\text { Non-adaptive intelligibility } \\
\text { score in quiet (-5 dB SNR) }\end{array}$ & Front & Front & $91.84 \pm 6.3 \%$ \\
\hline $\begin{array}{l}\text { Non-adaptive intelligibility } \\
\text { score in quiet (0 dB SNR) }\end{array}$ & Front & Front & $98.87 \pm 1.5 \%$ \\
\hline $\begin{array}{l}\text { Non-adaptive intelligibility } \\
\text { score in quiet (5 dB SNR) }\end{array}$ & Front & Front & $99.38 \pm 1.4 \%$ \\
\hline $\begin{array}{l}\text { Non-adaptive intelligibility } \\
\text { score in quiet (10 dB SNR) }\end{array}$ & Front & Front & $99.53 \pm 1.3 \%$ \\
\hline $\begin{array}{l}\text { Non-adaptive intelligibility } \\
\text { score in quiet (-10 dB SNR) }\end{array}$ & Front & Rear & $95.01 \pm 4.6 \%$ \\
\hline $\begin{array}{l}\text { Non-adaptive intelligibility } \\
\text { score in quiet (-5 dB SNR) }\end{array}$ & Front & Rear & $98.95 \pm 1.5 \%$ \\
\hline $\begin{array}{l}\text { Non-adaptive intelligibility } \\
\text { score in quiet ( } 0 \mathrm{~dB} \text { SNR) }\end{array}$ & Front & Rear & $99.27 \pm 1.6 \%$ \\
\hline $\begin{array}{l}\text { Non-adaptive intelligibility } \\
\text { score in quiet ( } 5 \mathrm{~dB} \text { SNR) }\end{array}$ & Front & Rear & $99.65 \pm 1 \%$ \\
\hline $\begin{array}{l}\text { Non-adaptive intelligibility } \\
\text { score in quiet (10 dB SNR) }\end{array}$ & Front & Rear & $99.81 \pm 0.5 \%$ \\
\hline
\end{tabular}

Table 3. Test statistics of the Turkish matrix test for a grouping variable of direction (front versus rear)

Adaptive matrix SRT in noise (50\%)

U $\quad \mathrm{p}$

Non-adaptive intelligibility score in noise (SNR: -10dB)

$154.5<0.0010$

Non-adaptive intelligibility score in noise (SNR: -5 dB)

0.0 $<0.0010$

Non-adaptive intelligibility score in noise (SNR: $0 \mathrm{~dB}$ )

$2285.5 \quad 0.006$

Non-adaptive intelligibility score in noise (SNR: $+5 \mathrm{~dB}$ )

$2692.5 \quad 0.170$

Non-adaptive intelligibility score in noise (SNR: $+10 \mathrm{~dB}$ )

$2793.0 \quad 0.326$

dB: Decibel, SNR: signal to noise ratio, SRT: speech reception threshold 


\begin{tabular}{l|l|l|}
$\begin{array}{l}\text { Table 4. Test statistics of the matrix test for a grouping } \\
\text { variable of performance differences. }\end{array}$ & \multicolumn{1}{l}{$\mid$} \\
\hline $\begin{array}{l}\text { Performance difference at different SNR } \\
\text { values (noise in front) }\end{array}$ & U & $\mathbf{p}$ \\
\hline$-10 \mathrm{~dB}$ SNR vs $-5 \mathrm{~dB}$ SNR & 0.000 & $<0.001$ \\
\hline$-5 \mathrm{~dB}$ SNR vs $0 \mathrm{~dB}$ SNR & 468.0 & $<0.001$ \\
\hline $0 \mathrm{~dB}$ SNR vs $+5 \mathrm{~dB}$ SNR & 2550.5 & 0.101 \\
\hline$+5 \mathrm{~dB}$ SNR vs +10dB SNR & 2887.0 & 0.711 \\
\hline $\mathrm{dB}$ : Decibel; SNR: signal to noise ratio & & \\
\hline
\end{tabular}

The matrix test was developed to remove this limitation and normalized to normal hearing by adapting to different languages. The literature shows that the normalizations were made on different numbers of participants. For example, in a study consisting 20 participants with normal hearing, the mean SRT of the German matrix test was $-7.1 \pm 0.2 \mathrm{~dB}$ (4). In the Finnish matrix test, the SRT was $-9.7 \pm 0.7 \mathrm{~dB}(5)$. In this study, the number of participants was 77 , and the mean SRT was $-7.92 \pm 0.8 \mathrm{~dB}$.

Because patients using hearing aids and $\mathrm{Cls}$ are tested in free field in this study, normalization values for these situations were obtained. Therefore, the tests were made in free field, and speech and noise stimuli were given from loudspeakers. The results can be discussed under the following headings.

The influence of direction to understand speech in noise: As sound travels through the external ear canal, diffractions and resonance are produced due to the head and the structure of the pinna and concha. These diffractions and resonance cause linear distortions in the transfer characteristics of the external ear canal. This change in the transfer characteristics of the external ear canal provides important cues for speech understanding in noise. Nilsson et al. (10) measured the speech discrimination thresholds of 150 young adults in the presence of noise using HINT test and placing loudspeakers in different positions. In the study, the speech stimulus was presented at $0^{\circ}$, and the noise stimulus at $0^{\circ}, 90^{\circ}$, and $270^{\circ}$ azimuth. The study showed that the spatial separation between the speech and noise lowered the speech discrimination thresholds by an average of $7.42 \mathrm{~dB}$.

With the aim of measuring the directional effects on intelligibility, individuals in this study were assessed by giving noise stimuli from the front and rear directions at different SNRs. Different SDSs were obtained at the same SNR when the speech stimulus was at $0^{\circ}$, and the noise stimulus was presented at $0^{\circ}$ and $180^{\circ}$ azimuth. For example, Table 3 shows that at the SNR of -10 $\mathrm{dB}$, the subjects' ability to discern speech differed significantly (noise, $0^{\circ}$ and $180^{\circ}$ azimuth, $31.10 \pm 11.9$ and 95.01 \pm 4.6 ). Similar results were obtained at $-5 \mathrm{~dB} S N R(p<0.05)$. However, as given in Table 3, for SNR of $0,+5$, and $+10 \mathrm{~dB}$, the participants' ability to understand speech was at a maximum level, independent from the noise and location of the signal. Therefore, a statistical difference in intelligibility scores was not found when the noise direction was changed for those SNRs. While comparing the performance between the cases when the noise was from the front and rear directions, it was thought that the significant improvement in the SRT values was due to the shadow effects of the head, pinna, and concha. When noise comes from behind, the person's ability to understand speech improves, and they are able to distinguish speech in lower SNRs. These data are similar to other studies in the literature (11). Based on this result, it is thought that when the SNR is low (such as in classroom), positioning the speech source in front of the listener and the noise in the back will increase speech comprehension performance.

The effect of level of noise on understanding speech: As shown in Figure 2, when the speech and noise stimuli are from the front, the mean speech intelligibility score values decrease much more as the SNR value decreases. Table 4 shows these performance differences. As shown in the table, while the performance differences between 10 and $5 \mathrm{~dB}$ SNRs and between 5 and $0 \mathrm{~dB}$ SNRs are statistically insignificant, the performance differences between 0 and $-5 \mathrm{~dB}$ SNRs and between -5 and $-10 \mathrm{~dB}$ SNRs are statistically significant $(p<0.05)$. This result shows that at low SNRs, the mean intelligibility scores are worse, even in normal-hearing individuals. This causes difficulty in understanding speech.

This performance reduction is observed even at higher SNRs in individuals using $\mathrm{Cl}$ or hearing aid. According to Polat et al. (12), the mean intelligibility performance difference between +5 and $0 \mathrm{~dB}$ SNRs was approximately $14 \%$ when both stimuli were given from the front in $\mathrm{Cl}$ users. According to the results in this study, the performance difference at the same SNRs is $<1 \%$. When the results of both studies are compared, individuals using $\mathrm{Cls}$ have been shown to be more affected by noisy environments.

\section{Study Limitations}

Our study has some limitations. First, because sex is not supposed to be a factor in hearing performance at this age group, the number of men and women were not kept equal in the study group. Second, the data were obtained from a limited group; thus, the results may not reflect the general population. Besides, the volunteers who agreed to participate in the survey consisted of university students or hospital personnel. Therefore, the results may be influenced by the education level of the study group.

\section{CONCLUSION}

This study aimed to determine the speech intelligibility performance of young adults with normal hearing in quiet and noisy free fields for different SNRs. Studies in the literature have shown that the scores of non-native participants are much lower, even if they have the same hearing thresholds as native speakers (13). For this reason, every patients' test of understanding speech in noise should be conducted in their native language. The normalization data were obtained by increasing the number of people and by choosing only native Turkish speakers.

This normalization data are more valuable for free-field tests because the tests in this study were performed in free field. 
These data can be used as a guide to assess speech recognition performance of $\mathrm{Cl}$ and hearing aid users.

Acknowledgments: The authors would like to thank all participating subjects for their cooperation and Audiology M.Sc. Students Ahmet, SH, Çınar M., and Kanak C. for their efforts in data collection. The authors would also like to thank Mr. Polat, E. for his help in the statistical analysis.

Ethics Committee Approval: Ethics committee approval was received from the İstanbul university-Cerrahpaşa, Cerrahpaşa Faculty of Medicine Clinical Research Ethics Committee for approval of the study (approval number: 83045809-604.01.02)

Informed Consent: All participants were informed in detail about the procedures of this study and signed an informed consent form.

Peer-review: Externally peer-reviewed.

Author Contributions: Concept - Z.P., A.A.; Design - Z.P., A.A.; Data Collection and/or Processing - Z.P.; Analysis and/ or Interpretation - Z.P., A.A.; Literature Search - Z.P.; Writing Manuscript - Z.P.

Conflict of Interest: The authors have no conflict of interest to declare.

Financial Disclosure: The authors declared that this study has received no financial support.

\section{REFERENCES}

1. Ozimek E, Kutzner D, Warzybok A. Speech intelligibility determined with various tests presented against noise. Proc Eur Conf Noise Control 2008; 123: 2323-8.

2. Smits C, Kapteyn TS, Houtgast T. Development and validation of an automatic speech-in-noise screening test by telephone. Int J Audiol 2004; 43: 15-28.

3. Hochmuth S, Brand T, Zokoll MA, Castro FZ, Wardenga N, Kollmeier B. A Spanish matrix sentence test for assessing speech reception thresholds in noise. Int J Audiol 2012; 51: 536-44.
4. Wagener KC, Kuhnel V, Kollmeier B, Brand T, Kollmeier B. Entwicklung und Evaluation eines Satztests für die deutsche Sprache Teil II: Optimierung des Oldenburger Satztests Development and evaluation of a German sentence test Part 11: Optimization of the Oldenbu rg sentence test. Z Audiol 1999; 38: 44-56.

5. Dietz A, Buschermöhle $M$, Aarnisalo AA, Vanhanen A, Hyyrynen $T$, Aaltonen $\mathrm{O}$, et al. The development and evaluation of the Finnish Matrix Sentence Test for speech intelligibility assessment. Acta Otolaryngol 2014;1 34: 728-37.

6. Zokoll MA, Fidan D, Türkyılmaz D, Hochmuth S, Ergenç I, Sennaroğlu G, et al. Development and evaluation of the Turkish matrix sentence test. Int J Audiol 2015; 54(Suppl 2): 51-61.

7. Zokoll MA, Hochmuth S, Warzybok A, Wagener KC, Buschermöhle M, Kollmeier B. Speech-in-noise tests for multilingual hearing screening and diagnostics. Am J Audiol 2013; 22: 175-8.

8. Killion MC, Niquette PA. What can the pure-tone audiogram tell us about a patient $\square$ s SNR loss? Hear J 2000; 53: 46-8.

9. Killion MC, Niquette PA, Gudmundsen GI, Revit LJ, Banerjee S. Development of a quick speech-in-noise test for measuring signalto-noise ratio loss in normal-hearing and hearing-impaired listeners. J Acoust Soc Am 2004; 116: 2395-405.

10. Nilsson M, Gelnett D, Sullivan J, Soli SD, Goldberg RL. Norms for the hearing in noise test: The influence of spatial separation, hearing loss, and English language experience on speech reception thresholds. J Acoust Soc Am 1992; 92: 2385-8.

11. Wimmer W, Weder S, Caversaccio M, Kompis M. Speech intelligibility in noise with a pinna effect imitating cochlear implant processor. Otol Neurotol 2016; 37: 19-23.

12. Polat $Z$, Bulut $E$, Ataş $A$. Assessment of the speech intelligibility performance of post lingual cochlear implant users at different signal-tonoise ratios using the turkish matrix test. Balkan Med J 2016; 33: 532-8

13. Marinova-Todd SH, Siu CK, Jenstad LM. Speech audiometry with nonnative English speakers: The use of digits and Cantonese words as stimuli. Can J Speech-Language Pathol Audiol 2011; 35: 220-7. 